\title{
Desempenho da tecnologia dos eritrócitos magnetizados (E.M.® Technology) nos testes imunoematológicos
}

\section{Erythrocytes magnetized technology (E.M. ${ }^{\circledR}$ Technology) performance in immunohematology assays}

\author{
Shirley L. Castilho ${ }^{l}$ \\ Verônica Prearo ${ }^{2}$ \\ Kátia S. Rodrigues ${ }^{2}$ \\ Maria E. L. Duarte
}

\begin{abstract}
A tecnologia dos eritrócitos magnetizados (E.M. ${ }^{\circledR}$ Technology) é uma grande inovação nos ensaios imunoematológicos. Os testes são realizados manualmente na estação de trabalho Freelys ${ }^{\circledR}$ Nano ou no equipamento automatizado Qwalys ${ }^{\circledR}$ (Diagast, Loos, France). O método utiliza hemácias magnetizadas e uma placa magnética substitui a centrifugação. As microplacas para a classificação sangüinea e fenotipagem Rh e $K$ contêm anti-soros monoclonais IgM. As microplacas destinadas a pesquisa de anticorpos irregulares (PAI) e prova cruzada (PC) contêm antiglobulina humana (AGH) monoclonal murina: anti-IgG na PAI e na PC anti-IgG + anti-IgM de baixo título para detectar anticorpos $A B O$. Na PAI e na PC, as reações acontecem na camada contendo AGH (imunocaptura) e visa detectar anticorpos $\operatorname{IgG}$. A utilização de um meio de alta densidade possibilita a utilização da AGH sem lavagens prévias. Na avaliação da E.M. ${ }^{\circledR}$ Technology na classificação sangüínea, Fenotipagem, PAI e PC, na estação

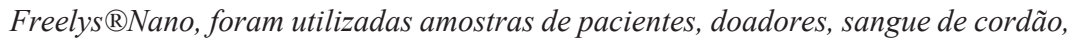
hemácias de pacientes com teste de Coombs direto positivo e concentrados de hemácias. Todas as amostras foram paralelamente testadas em gel-teste (Diamed e Grifols). A concordância entre a E.M. ${ }^{\circledR T e c h n o l o g y ~ e ~ o ~ g e l-t e s t e ~ f o i: ~ 100 \% ~ n a ~ c l a s s i f i c a c ̧ a ̃ o ~ A B O ~ e ~}$ RhD e na fenotipagem $\mathrm{Rh} / \mathrm{K}$, 94,6\% na PAI e 92,3\% na PC. A sensibilidade da E.M. ${ }^{\circledR}$ Technology na detecção de anticorpos $\operatorname{Ig} G$ foi 95,5\% em ambos os métodos. A E.M. ${ }^{\circledR}$ Technology mostrou um bom desempenho nos testes efetuados. Rev. Bras. Hematol. Hemoter. 2008;30(5):374-378.
\end{abstract}

Palavras-chave: Eritrócitos magnetizados (E.M. ${ }^{\circledR}$ Technology); testes imunoematológicos; aglutinação em fase sólida; pesquisa de anticorpos irregulares; prova de cruzada.

\section{Introdução}

A era científica da transfusão teve início em 1901 com a descoberta do sistema $\mathrm{ABO}$ por Landsteiner. ${ }^{1}$ A partir daí, outros sistemas eritrocitários foram descritos e novos reagentes surgiram com o objetivo de evidenciar a reação antígeno-anticorpo através da hemaglutinação. A descrição do uso da albumina bovina a $22 \%$ na detecção de anticorpos incompletos por Diamond e Adelson ${ }^{2,3}$ e a descrição da apli- cação da antiglobulina humana (AGH) na detecção de anticorpos IgG por Coombs et al. ${ }^{4}$ trouxeram avanços importantes para as técnicas imuno-hematológicas. Os testes tradicionais em placa de opalina foram substituídos pelos tubos de hemólise e microplacas. Nos anos 80 , o gel-teste desenvolvido por Lapierre et al. ${ }^{5}$ revolucionou o mercado devido à possibilidade de utilização da AGH sem a etapa prévia de lavagem das hemácias. A produção dos reagentes monoclonais por Milstein e Köhler ${ }^{6}$ foi outro grande avanço na imuno-

\footnotetext{
${ }^{I}$ Médica. Chefe do laboratório de Imunogenética do Hemorio - Rio de Janeiro-RJ.

${ }^{2}$ Bióloga do Laboratório de Imunogenética do Hemorio - Rio de Janeiro-RJ.

${ }^{3}$ Médica. Chefe do Serviço de Hemoterapia do Hemorio - Rio de Janeiro-RJ.

Laboratório de Imunogenética do Instituto Estadual Arthur de Siqueira Cavalcanti - Hemorio - Rio de Janeiro-RJ.
}

Correspondência: Shirley Lopes de Castilho

Rua Frei Caneca 8, sala 232 - Centro

20211-030 - Rio de Janeiro, RJ - Brasil

Tel.: 5521 2299-9433

E-mail: shirley.castilho@hemorio.rj.gov.br 
ematologia eritrocitária, pois, entre outros benefícios, resolveu os problemas relacionados às freqüências antigênicas que dificultavam a obtenção de anticorpos para aplicações diagnósticas. A utilização de equipamentos automáticos trouxe agilidade na execução e liberação dos testes imunoematológicos da rotina dos doadores de sangue. A E.M. ${ }^{\circledR}$ Technology (Diagast, Loos, France) é uma nova metodologia baseada na utilização de hemácias magnetizadas. Os ensaios se dão em microplacas impregnadas com reagentes nas quais são dispensadas as amostras. Como as hemácias são magnetizadas, ao submetermos a microplaca a uma placa magnética, as hemácias migram em direção ao fundo das cavidades, dispensando a etapa de centrifugação. Os ensaios podem ser realizados manualmente na estação de trabalho Freelys ${ }^{\mathbb{R}}$ Nano ou totalmente automatizados no equipamento Qwalys ${ }^{\circledR}$ (Diagast, Loos, France). Esta metodologia assim como o gel-teste, possibilita o uso da antiglobulina humana sem lavagens prévias proporcionando agilidade em grandes rotinas.

\section{Material e Método}

Classificação $A B O, R h D$ e fenotipagem para os antígenos $\mathrm{RH} 2$, RH3, RH4, RH5 e KEL1

Para estes ensaios foram selecionadas 420 amostras assim distribuídas: 96 amostras de concentrados de hemácias no $15^{\circ}$ e $25^{\circ}$ dia de estocagem, 226 amostras de pacientes com doenças hematológicas, 50 amostras de sangue de cordão umbilical sem lavagem prévia e 48 amostras com Teste da Antiglobulina Humana Direto (TAD) positivo (Tabela 1).

Tabela 1. Distribuição das amostras destinadas à Classificação $\mathrm{ABO}, \mathrm{RhD}$ e fenotipagem para os antígenos $\mathrm{RH} 2, \mathrm{RH} 3, \mathrm{RH} 4, \mathrm{RH} 5$ e KEL1

\begin{tabular}{lc}
\hline \multicolumn{1}{c}{ Amostras } & Número \\
\hline Segmentos de bolsa de concentrado de hemácias & 96 \\
Pacientes com doença hematológica & 226 \\
Sangue de cordão umbilical & 50 \\
Hemácia com TAD positivo & 48 \\
Total & 420 \\
\hline
\end{tabular}

Na E.M. ${ }^{\circledR}$ Technology, as microplacas destinadas à classificação $\mathrm{ABO}, \mathrm{RhD}$ e fenotipagem eritrocitária são impregnadas com reagentes monoclonais IgM anti-A, anti-B, anti-AB, anti-D, anti-C, anti-c, anti-E, anti-e e anti-K, uma cavidade contendo apenas reagentes estabilizadores (controle negativo) e duas cavidades vazias destinadas a classificação ABO reversa. As hemácias a testar foram suspensas em uma solução magnetizadora e tratadas com a enzima bromelina. A seguir, $40 \mu \mathrm{L}$ desta suspensão foram dispensadas nas cavidades das microplacas contendo os antisoros e na cavidade destinada ao controle. A classificação reversa foi realizada dispensando o plasma da amostra e as hemácias teste $\mathrm{A}_{1}$ e $\mathrm{B}$, também magnetizadas, em duas outras cavidades. Após dez minutos de incubação à temperatura ambiente, as microplacas foram colocadas na placa magnética da estação Freelys ${ }^{\circledR}$ Nano (Diagast, Loos, France). O campo magnético atrai as hemácias magnetizadas para o fundo das cavidades, formando um botão. Após agitação controlada no homogeneizador da estação Freelys ${ }^{\mathbb{R}}$ Nano, as reações foram analisadas segundo orientação do fabricante. Em caso de resultado positivo, o botão de hemácias permanece estável, permitindo quantificar a reação em cruzes ( 1 a $4+$ ). Não havendo reação antígeno-anticorpo (resultado negativo), o botão se desfaz sob agitação e observa-se um aspecto homogêneo. Todos os ensaios também foram efetuados paralelamente em gel-teste (Diamed AG, Cressier, Switzerland). A realização dos testes e as interpretações dos resultados em gel-teste foram realizadas conforme instruções inclusas no kit.

\section{Pesquisa de anticorpos irregulares (PAI)}

Para estes testes foram selecionadas 186 amostras, assim distribuídas: 94 amostras de doadores de sangue recém-coletadas em EDTA e 92 amostras de plasma de pacientes armazenadas a $-20^{\circ} \mathrm{C}$. Das 92 amostras de pacientes, 15 apresentavam PAI negativa e 67 PAI positiva. As amostras apresentavam anticorpos com as seguintes especificidades: 10 anti-D, 4 anti-D+C, 15 anti-C, 17 anti-E, 1 antic, 4 anti-e, 7 anti- $\mathrm{K}, 1$ anti-Jk ${ }^{\mathrm{a}}, 1$ anti-Jk ${ }^{\mathrm{b}}, 1$ anti-Fy ${ }^{\mathrm{a}}, 2$ antiFy3, 1 anti-Le ${ }^{b}, 1$ anti-S, 1 anti-s e 1 anti-U. Estes anticorpos foram previamente identificados através das técnicas em tubos de hemólise a TA e a $37^{\circ} \mathrm{C}$, em Gel/Liss) Coombs e gel/papaínaDiamed. Na E.M. ${ }^{\circledR}$ Technology, a pesquisa de anticorpos irregulares é realizada em microplacas impregnadas com antiglobulina monoclonal murina anti-IgG. Para a triagem de anticorpos foi utilizado um conjunto de duas hemácias magnetizadas na concentração de 1\%. A técnica consiste em dispensar, em duas cavidades consecutivas da microplaca, $60 \mu \mathrm{l}$ de um meio de alta densidade com a finalidade de impedir o contato direto do plasma com a AGH durante a fase de incubação, inativando-a. A seguir são adicionados $60 \mu \mathrm{l}$ de um meio de baixa forca iônica, $50 \mu \mathrm{l}$ das hemácias de triagem I e II magnetizadas e $15 \mu 1$ de plasma. Após uma incubação de vinte minutos a $37^{\circ} \mathrm{C}$ na estação Freelys ${ }^{\mathbb{N}}$ Nano, a microplaca é colocada na placa magnética. Somente as hemácias magnetizadas migrarão até a camada imuno-ativa. Se houver anticorpos séricos dirigidos contra antígenos presentes nas hemácias de triagem, estes se fixarão nas hemácias. Quando as hemácias entrarem em contato com a AGH anti-IgG, impregnada nas cavidades da microplaca, sua fração Fab irá se ligar a fração Fc das IgG presentes nas hemácias sensibilizadas retendo-as nesta camada e determinando um aspecto homogêneo. Não havendo reação antígeno-anticorpo, as hemácias migrarão para o fundo da microplaca formando um botão. As leituras 
são quantificadas segundo instruções do fabricante. $\mathrm{Na}$ PAI, o padrão de leitura é inverso ao da classificação sangüínea e fenotipagem. Todos os testes foram realizados paralelamente na técnica de gel da empresa Diamed. As cartelas de Coombs contêm gel sephadex impregnado com antiglobulina anti-IgG e anti-C3d. Com o objetivo de melhor padronização dos ensaios e evitar divergências de resultados devido a características das hemácias de triagem, o mesmo conjunto de hemácias de triagem I e II, não magnetizadas, foi utilizado, e as hemácias foram suspensas em solução de Liss na concentração a $0,8 \%$. Os ensaios e a interpretação dos resultados foram realizados conforme instruções do fabricante. Em caso de divergências de resultados, visando a detecção de anticorpos frios e de reações inespecíficas, era realizada a PAI em tubos de hemólise com leitura a TA e a $37^{\circ} \mathrm{C}$ após a adição de albumina bovina a $22 \%$ e AGH poli-especifica $(\operatorname{IgG}+\mathrm{C} 3 \mathrm{~d})$.

\section{Prova cruzada (PC)}

Para a PC foram selecionadas 117 amostras, assim distribuídas: 74 amostras desconhecidas de plasma de pacientes. Em todos os casos era selecionado um concentrado de hemácias segundo classificação $\mathrm{ABO}$ e Rh do paciente. Foram selecionadas também 43 amostras armazenadas de plasmas de doadores contendo anticorpos irregulares já identificados através da técnica em tubos de hemólise com leitura a TA, gel/Liss/Coombs e gel/papaína Diamed. Destas, 31 apresentavam anticorpos IgG e 12 anticorpos IgM. As amostras eram assim distribuídas: 5 Anti-D, 2 Anti-D+C, 10 Anti-E, 2 Anti-Fy ${ }^{\mathrm{a}}, 1$ Anti-Fy3, 2 Anti-Jk ${ }^{\mathrm{a}}$, 7 Anti-K, 2 Anti-Le ${ }^{\mathrm{x}}, 5$ anti$\mathrm{Le}^{\mathrm{a}}, 2$ anti-Le ${ }^{\mathrm{b}}$ e 5 anti-M. Em todos os casos era selecionado um concentrado de hemácias segundo classificação $\mathrm{ABO}$ e Rh do paciente e positiva para os antígenos correspondentes aos anticorpos séricos de cada amostra. A prova cruzada na E.M. ${ }^{\circledR}$ Technology é uma técnica de imunocaptura semelhante à PAI. No entanto, as microplacas destinadas a PC contêm, além da antiglobulina monoclonal murina anti-IgG, uma anti-IgM de baixo título com o objetivo de identificar anticorpos do sistema ABO. Com o mesmo objetivo da PAI, para evitar a inativação da $\mathrm{AGH}$, em cada cavidade da microplaca são dispensados $40 \mu \mathrm{L}$ de um meio de alta densidade. A seguir, $40 \mu \mathrm{L}$ de um meio de baixa forca iônica, $20 \mu \mathrm{L}$ da amostra de plasma e, por fim, $15 \mu \mathrm{L}$ das hemácias do segmento da bolsa, previamente magnetizadas conforme instruções da Diagast. Após vinte minutos de incubação a $37^{\circ} \mathrm{C}$ na incubadora da estação Freelys ${ }^{\circledR}$ Nano, cada microplaca é colocada na placa magnética e, em seguida, os resultados são interpretados conforme o padrão estabelecido pelo fabricante. Na PC, o padrão de leitura do teste é semelhante ao da PAI. Em todas as amostras, foram realizadas paralelamente a PC na técnica gel-Liss-Coombs utilizando-se cartelas da marca Grifols, pois estas, como as microplacas da $\mathrm{EM}^{\circledR}$ Technology, além de antiglobulina anti-IgG e anti-C3d, contêm uma AGH anti-IgM. Nos casos onde houve falha na deteç̧ão de anticorpos, foram realizadas novas provas cruzadas na técnica convencional em tubos de hemólise com análise das reações a temperatura ambiente e a $37^{\circ} \mathrm{C}$, após a adição de albumina bovina a $22 \%$ e AGH.

\section{Resultados}

Classificação $A B O, R h D$ e fenotipagem eritrocitária Todas as $420(100 \%)$ amostras apresentaram resultados concordantes em ambas as metodologias. Nas 94 amostras de concentrados de hemácias testadas no $15^{\circ}$ e $25^{\circ}$ dia de estocagem observamos na E.M. ${ }^{\circledR}$ Technology que os resultados positivos apresentavam intensidade de reação de $2+$ a 4+. Em duas amostras K+ houve diminuição na intensidade das reações relacionada com o tempo de estocagem de $2+\left(15^{\circ} \mathrm{dia}\right)$ para $1+\left(25^{\circ} \mathrm{dia}\right)$. Em gel-teste, o padrão positivo foi de $3+$ a $4+$ e não houve diminuição da intensidade de reação relacionada à estocagem. Das 50 amostras de sangue de cordão, 49 apresentaram padrão positivo com intensidade de $3+$ a $4+$ em ambas as metodologias. Em um caso, na fenotipagem para o antígeno $\mathrm{K}$, a intensidade da reação foi de 1+ na E.M. ${ }^{\circledR}$ Technology, enquanto em gel-teste foi de 4+. Nas 226 amostras de pacientes observamos, em ambas as técnicas, uma intensidade de reação de $3+$ a $4+$. Em três casos, uma potente auto-aglutinina fria invalidou os resultados em ambas as metodologias. Das 48 amostras com TAD positivo, devido a IgG e complemento, 47 apresentaram resultados concordantes e padrão positivo com intensidade de $3+$ a 4+. Em um caso, a intensidade da reação na fenotipagem para o antígeno $\mathrm{K}$ foi de $1+$ na E.M. ${ }^{\circledR}$ Technology enquanto em gel-teste foi de $4+$.

\section{Pesquisa de anticorpos irregulares}

Todas as $94(100 \%)$ amostras recém-coletadas de doadores de sangue apresentaram resultados negativos nas duas metodologias.

Nas 92 amostras de plasma de pacientes observamos que, das 25 amostras com PAI negativa selecionadas, 18 (72\%) eram negativas em ambas as metodologias e $7(28 \%)$ apresentavam resultados fracamente positivos $(1+)$ e duvidosos na E.M. ${ }^{\circledR}$ Technology (Tabela 2 ). Estes resultados não se reproduziram na técnica em tubos de hemólise.

Das 67 amostras positivas, $64(95,5 \%)$ eram positivas em ambas as metodologias. A Tabela 3 demonstra as especificidades dos anticorpos e os resultados nas duas metodologias.

Em dois casos (anti-E), os resultados foram negativos em ambas as metodologias. Em outros dois casos foram observados resultados discordantes. Em um deles, o resultado era positivo apenas em gel-teste (anti-Le ${ }^{b}$ ) e em outro (anti-E) na E.M.®Technology. Nestes dois casos discordantes, a presença do anti-Le ${ }^{\mathrm{b}}$ foi confirmada na técnica em tubos de hemólise na leitura imediata à TA. A presença do anti-E foi detectada a $37^{\circ} \mathrm{C}$ após adição de $\mathrm{AGH}$ (Coombs 
Tabela 2. Resultado da PAI em amostras negativas congeladas selecionadas

\begin{tabular}{ccccc}
\hline \multirow{2}{*}{$\begin{array}{c}\text { No de } \\
\text { Amostras }\end{array}$} & \multicolumn{2}{c}{ E.M.@Technology } & \multicolumn{2}{c}{ Gel-teste } \\
\cline { 2 - 5 } & $\begin{array}{c}\text { Amostras } \\
\text { positivas }\end{array}$ & $\begin{array}{c}\text { Amostras } \\
\text { negativas }\end{array}$ & $\begin{array}{c}\text { Amostras } \\
\text { positivas }\end{array}$ & $\begin{array}{c}\text { Amostras } \\
\text { negativas }\end{array}$ \\
\hline 25 & 7 & 18 & 0 & 25 \\
$\%$ & $28 \%$ & $72 \%$ & - & $100 \%$ \\
\hline
\end{tabular}

Tabela 3. Especificidade dos anticorpos nas amostras PAI positiva e os resultados nas duas metodologias

\begin{tabular}{cccc}
\hline $\begin{array}{c}\text { Especificidade } \\
\text { do anticorpo }\end{array}$ & $\begin{array}{c}\text { Número de } \\
\text { amostras }\end{array}$ & $\begin{array}{c}\text { Amostras } \\
\text { positivas na } \\
\text { E.M.@Technology }\end{array}$ & $\begin{array}{c}\text { Amostras } \\
\text { positivas } \\
\text { em gel-teste }\end{array}$ \\
\hline Anti-D & 10 & 10 & 10 \\
Anti-D+C & 4 & 4 & 4 \\
Anti-C & 15 & 15 & 15 \\
Anti-E & 17 & 15 & 14 \\
Anti-C & 1 & 1 & 1 \\
Anti-e & 4 & 4 & 4 \\
Anti-K & 7 & 7 & 7 \\
anti-Jk ${ }^{a}$ & 1 & 1 & 1 \\
Anti-Jk & 1 & 1 & 1 \\
anti-Fy & 1 & 1 & 1 \\
anti-Fy 3 & 2 & 2 & 2 \\
Anti-Le ${ }^{b}$ & 1 & 0 & 1 \\
Anti-S & 1 & 1 & 1 \\
anti-s & 1 & 1 & 1 \\
Anti-U & 1 & 1 & 64 \\
\hline Total & 67 & 64 & $95 \%$ \\
\hline \% & & $95,5 \%$ & 1 \\
\hline positivo & & 1 & 5
\end{tabular}

$\%$ positivo $95,5 \%$

Tabela 4. Resultados da PAI nas amostras positivas discordantes

\begin{tabular}{cccccc}
$\begin{array}{c}\text { Especificidade } \\
\text { dos anticorpos }\end{array}$ & $\begin{array}{c}\text { Natureza do } \\
\text { anticorpo }\end{array}$ & $\begin{array}{c}\text { E.M. }{ }^{\circledR} \\
\text { Technology }\end{array}$ & $\begin{array}{c}\text { Gel- } \\
\text { teste }\end{array}$ & $\begin{array}{c}\text { Tubo } \\
\text { TA }\end{array}$ & $\begin{array}{c}\text { Tubo } \\
37 \\
\text { AGH }\end{array}$ \\
\hline Anti-Le & $\lg \mathrm{M}$ & $\mathrm{N}$ & $1+$ & $2+$ & $\mathrm{N}$ \\
Anti-E & $\lg \mathrm{G}$ & $1+$ & $\mathrm{N}$ & $\mathrm{N}$ & $1+$ \\
\hline
\end{tabular}

albuminoso) e com hemácias tratadas por bromelina. Nos dois casos onde houve falha na detecção do anti-E, os resultados também foram negativos em tubos de hemólise na leitura imediata à TA e a $37^{\circ} \mathrm{C}$ após adição de $\mathrm{AGH}$. Consultando os dados de estudos anteriores, estas amostras eram positivas apenas com hemácias tratadas pela enzima papaína. A Tabela 4 resume os resultados das amostras discordantes na PAI.

\section{Prova cruzada}

As $74(100 \%)$ amostras de plasma de pacientes apresentaram resultados negativos nas duas metodologias. Das 43 amostras de plasmas de doadores contendo anticorpos irregulares e compatibilizados com hemácias positivas para o
Tabela 5. Característica das amostras com resultados negativos na E.M.®Technology

\begin{tabular}{ccccccc}
\hline $\begin{array}{c}\text { Especificidade } \\
\text { dos } \\
\text { anticorpos }\end{array}$ & $\begin{array}{c}\text { Natureza } \\
\text { dos } \\
\text { anticorpos }\end{array}$ & $\begin{array}{c}\text { E.M. } \\
\text { Technology }\end{array}$ & $\begin{array}{c}\text { Gel- } \\
\text { teste }\end{array}$ & $\begin{array}{c}\text { Tubo } \\
\text { TA }\end{array}$ & $\begin{array}{c}\text { Tubo } \\
37^{\circ} \mathrm{C} \\
\text { AGH }\end{array}$ \\
\hline 1 & Anti-Le & $\operatorname{lgM}$ & $\mathrm{N}$ & $1+$ & $1+$ & $\mathrm{N}$ \\
2 & Anti-Le $^{\mathrm{a}}$ & $\operatorname{lgM}$ & $\mathrm{N}$ & $2+$ & $2+$ & $\mathrm{N}$ \\
3 & Anti-Le $^{\mathrm{a}}$ & $\operatorname{lgM}$ & $\mathrm{N}$ & $1+$ & $1+$ & $\mathrm{N}$ \\
4 & Anti-Le & $\operatorname{lgM}$ & $\mathrm{N}$ & $1+$ & $1+$ & $\mathrm{N}$ \\
5 & Anti-Le & $\operatorname{lgM}$ & $\mathrm{N}$ & $1+$ & $1+$ & $\mathrm{N}$ \\
6 & Anti-M & $\operatorname{lgM}$ & $\mathrm{N}$ & $1+$ & $2+$ & $\mathrm{N}$ \\
7 & Anti-M & $\operatorname{lgM}$ & $\mathrm{N}$ & $1+$ & $2+$ & $\mathrm{N}$ \\
8 & Anti-M & $\operatorname{lgM}$ & $\mathrm{N}$ & $1+$ & $2+$ & $\mathrm{N}$ \\
9 & Anti-M & $\operatorname{lgM}$ & $\mathrm{N}$ & $1+$ & $2+$ & $\mathrm{N}$ \\
\hline
\end{tabular}

Tabela 6. Característica das amostras com resultados negativos nas duas metodologias

\begin{tabular}{|c|c|c|c|c|c|}
\hline $\begin{array}{c}\text { Especificidade } \\
\text { dos } \\
\text { anticorpos }\end{array}$ & Natureza & $\begin{array}{c}\text { E.M.B } \\
\text { Technology }\end{array}$ & $\begin{array}{l}\text { Gel- } \\
\text { teste }\end{array}$ & $\begin{array}{c}\text { Tubo } \\
\text { TA }\end{array}$ & $\begin{array}{l}\text { Tubo } \\
37^{\circ} \mathrm{C} \\
\mathrm{AGH}\end{array}$ \\
\hline Anti-Le & $\lg G$ & $\mathrm{~N}$ & $\mathrm{~N}$ & $\mathrm{~N}$ & $\mathrm{~N}$ \\
\hline Anti-Le ${ }^{b}$ & $\lg M$ & $\mathrm{~N}$ & $N$ & $2+$ & $\mathrm{N}$ \\
\hline Anti-Le ${ }^{a}$ & $\lg M$ & $\mathrm{~N}$ & $N$ & W & $\mathrm{N}$ \\
\hline Anti-M & $\lg M$ & $\mathrm{~N}$ & $N$ & $2+$ & $\mathrm{N}$ \\
\hline
\end{tabular}

antígeno correspondente, observamos que nove (21\%) apresentavam resultados negativos apenas na E.M.®Technology e, em quatro $(9,4 \%)$ casos, os resultados eram negativos em ambas as metodologias. As Tabelas 5 e 6 demonstram a especificidades e comportamento dos anticorpos em cada metodologia.

\section{Discussão}

A E.M. ${ }^{\circledR}$ Technology, utilizando a estação Freelys ${ }^{\circledR}$ Nano, foi capaz de determinar corretamente a classificação $\mathrm{ABO}$, Rh e a fenotipagem eritrocitária para os antígenos, $\mathrm{RH} 2$, RH3, RH4, RH5 e KEL1 em amostras de concentrado de hemácias estocadas, sangue de cordão, amostras de pacientes com doenças hematológicas. A presença de IgG ou complemento sensibilizando as hemácias não impediu a interpretação dos resultados. Embora, em três casos, a intensidade das reações com hemácias $\mathrm{K}+$ tenha apresentado intensidade de $1+$ em amostras estocadas, não observamos resultados falso-negativos.

Na PAI, este estudo comparativo demonstrou que a E.M. ${ }^{\circledR}$ Technology, utilizando a estação Freelys ${ }^{\circledR N a n o, ~ f o i ~}$ capaz de detectar a presença de anticorpos IgG com especificidades contra os antígenos D, C, c, E, e, K, Jk ${ }^{\mathrm{a}}, \mathrm{Jk}^{\mathrm{b}}, \mathrm{Fy}^{\mathrm{a}}$, Fy3, S, s e U. Houve falha na detecção de um anticorpo frio anti-Le ${ }^{b}$. Este resultado era esperado, pois a PAI, na E.M. ${ }^{\circledR}$ Technology, visa a detecção apenas de anticorpos IgG. Observamos que anticorpos frios ainda são melhor detectados nas técnicas em tubos de hemólise. A falha na detecção de um caso de anticorpo anti-E em gel-teste pode estar relacionada a um erro técnico. Em dois outros casos onde houve 
falha de detecção do anticorpo anti-E na E.M.®Technology, em gel teste e na técnica em tubos, estes resultados apontam para perda destes anticorpos durante a estocagem. Os resultados falso-positivos observados na E.M.®Technology podem estar relacionados à utilização de plasma previamente congelado. $\mathrm{O}$ fabricante recomenda a utilização de amostras recém-coletadas.

$\mathrm{Na}$ PC, com as 74 amostras recém-coletadas, houve $100 \%$ de concordância nas duas metodologias. Das 43 amostras de plasmas apresentando anticorpos irregulares, a E.M. $囚 T e c h n o l o g y$ foi capaz de detectar $30(96,8 \%)$ das 31 amostras contendo anticorpos IgG. Nos 9 casos com resultados negativos apenas na E.M. ${ }^{\circledR}$ Technology, os anticorpos envolvidos eram IgM.

\section{Conclusões}

A E.M.®Technology é uma metodologia de fácil execução e econômica e utiliza pequeno volume de amostras. A estação Freelys Nano é uma plataforma pequena necessitando pouco espaço na bancada de trabalho. Na classificação $\mathrm{ABO}, \mathrm{RhD}$ e fenotipagem das 420 amostras houve $100 \%$ de concordância entre as metodologias. Na PAI e PC, a utilização de uma antiglobulina $\operatorname{IgG}$ e a incubação a $37^{\circ} \mathrm{C}$ permitirão a detecção apenas de anticorpos IgG. A RDC 153, de 14 de junho de 2004, enfatiza, para fins transfusionais, a importância na detecção de anticorpos clinicamente significantes, ou seja, aqueles que reagem a $37^{\circ} \mathrm{C}$ na fase da $\mathrm{AGH}$. A presença de anticorpos frios não representa riscos importantes na transfusão sangüínea. ${ }^{6} \mathrm{Na} \mathrm{PAI}$, a concordância entre as metodologias foi de $94,6 \%$. Na prova cruzada, a concordância foi de $92,3 \%$. A principal causa de divergência na PC está relacionada à presença de anticorpos IgM que não são detectados pela E.M.®Technology. Os resultados observados demonstram um bom desempenho da E.M. ${ }^{\circledR}$ Technology nos ensaios imunoematológicos.

\section{Abstract}

The erythrocytes magnetized technology (E.M. ${ }^{\circledR}$ Technology) is a great innovation in the field of blood banking. The tests can be performed manually on a Freelys ${ }^{\circledR}$ Nano workstation or on the fully-automated system QWALYS® (Diagast, Loos, France). This method does not require centrifugation steps thanks to the use of magnetic red blood cells and a magnetic plate. For blood grouping and $\mathrm{Rh} / \mathrm{K}$ phenotyping, the microplate contains monoclonal IgM antibodies. The wells of the microplate to perform antibody screening and cross-matching are coated with murine monoclonal anti-human globulin: anti-IgG for antibody screening and anti-IgG + anti-IgM for cross-matching. The E.M. ${ }^{\circledR}$ Technology is only able to detect IgG antibodies. A high-density medium layer avoids the necessity of rinsing before the antiglobulin reagent. To evaluate the performance of E.M. ${ }^{\circledR}$ Technology on a Freelys ${ }^{\circledR}$ Nano work station for blood grouping, Rh/K phenotyping, antibody screening and crossmatching, we selected samples from patients, blood donors, blood cords, red blood cells from patients with positive direct antiglobulin test (DAT) and red blood cells from storage blood bags. In parallel, the tests were performed using the gel-technique (Diamed and Grifols). The concordance between E.M. ( Technology and gel-test was $100 \%$ for blood grouping and $\mathrm{Rh} / \mathrm{K}$ phenotyping, $94.6 \%$ for antibody screening and $92.3 \%$ for cross-matching. The sensitivity to detect $\operatorname{Ig} G$ antibodies was $95.5 \%$ in both methods. The E.M. ${ }^{\circledR}$ Technology on a Freelys ${ }^{\circledR}$ Nano workstation provided good results in all the tests performed. Rev. Bras. Hematol. Hemoter. 2008;30 (5):374-378.

Key words: Erythrocytes magnetized (E.M. ${ }^{\circledR}$ Technology); immunohematology tests; hemagglutination in solid phase; antibody screening and cross-matching.

\section{Agradecimentos}

Márcia Otta, farmacêutica, gerente de Marketing e Desenvolvimento da Empresa Fresenius Kabi.

Valeria Livieiro Wakim, enfermeira especialista de produtos em Imunoematologia da Empresa Fresenius Kabi.

\section{Referências Bibliográficas}

1. Daniels G. Human Blood Groups, Cambridge, 1995, 737p.

2. Rumsey, Ciesielskic DJ. New protocols in serologic testing: a review of techniques to meet today's challenges. Immunohematology. 2000;16(4)3-9.

3. Diamond LK, Abelson NM. The detection of Rh sensitization: evaluations of tests for Rh antibodies. J Lab Clin Med. 1945; 30: 668-74.

4. Coombs RR, Mourant AE, Race RR. A new test for the detection of weak and "incomplete" Rh agglutinins. Br J Exp Pathol. 1945; 26: 255.

5. Lapierre Y, Rigal D, Adam J, et al. The gel test: a new way to detect red cell antigen-antibody reactions. Transfusion. 1990; 30(2):109-13.

6. Winter G, Milstein C. Man-made antibodies. Nature. 1991;349 (6307):293-9.

7. Judd WJ, Fullen DR, Steiner EA, Davenport RD, Knafl PC. Revisiting the issue: can the reading for serologic reactivity following 37 degrees C incubation be omitted? Transfusion. 1999;39(3):295-9.

Avaliação: Editor e dois revisores externos

Conflito de interesse: não declarado

Recebido: 31/01/2008

Aceito após modificações: 03/07/2008 